\title{
Autosomal dominant spastic paraplegia type 41
}

INSERM

\section{Source}

INSERM. (1999). Orphanet: an online rare disease and orphan drug data base. Autosomal dominant spastic paraplegia type 41. ORPHA:320355

Autosomal dominant spastic paraplegia type 41 is a pure form of hereditary spastic paraplegia characterized by onset in adolescence or early adulthood of slowly progressive spastic paraplegia, proximal muscle weakness of the lower extremities and small hand muscles, hyperreflexia, spastic gait and mild urinary compromise. 